Isabel de Oliveira e Silva Universidade Federal de Minas Gerais, UFMG

E-mail: isabel.os@uol.com.br

(D) http://orcid.org/0000-0003-2223-4548

Iza Rodrigues da Luz

Universidade Federal de Minas Gerais, UFMG

E-mail: izarodriguesluz@gmail.com

(D) https://orcid.org/0000-0002-4772-1329

Karina de Oliveira Santos Cordeiro Universidade Federal do Recôncavo da Bahia, UFRB

E-mail: koscordeiro@ufrb.edu.br

(D) https://orcid.org/0000-0002-9136-1383

Recebido em: 09/02/2018

Aprovado em: 23/03/2019

\section{Mapeamento de grupos de pesquisa e estudos sobre a educação infantil para as crianças residentes em áreas rurais da região sudeste do \\ Brasil}

\section{Isabel de Oliveira e Silva Iza Rodrigues da Luz Karina de Oliveira Santos Cordeiro}

\section{Resumo}

O artigo apresenta um mapeamento dos artigos, teses e dissertações da área da Educação que tiveram como objeto temáticas relacionadas à Educação Infantil para as crianças residentes em áreas rurais da Região Sudeste do Brasil, no período de 2012 a 2016. Abrangeu também um levantamento dos grupos de pesquisa da área da educação da Região Sudeste, para verificar se a temática era contemplada. Em diálogo com os relatórios da Pesquisa Nacional Caracterização das práticas pedagógicas com crianças de 0 a 6 anos residentes em área rural, publicados no site do Ministério da Educação, objetivou conhecer o que se produziu sobre a temática depois da referida pesquisa. A metodologia consistiu em pesquisa bibliográfica e busca em cadastro de grupos de pesquisa, todos disponíveis na web. Foram realizadas buscas nas seguintes fontes: a) Diretório de Grupos de Pesquisa do Conselho Nacional de Desenvolvimento Científico e Tecnológico (CNPq); b) relatórios da Pesquisa Nacional Caracterização das práticas pedagógicas com crianças de 0 a 6 anos residentes em área rural; c) banco de teses e dissertações da Coordenação de Aperfeiçoamento de Pessoal de Nível Superior (Capes); e d) o site da Scientific Eletronic Library Online (SciELO). Os resultados indicaram poucos avanços e que estamos distantes de conhecer a realidade das crianças pequenas de áreas não urbanas. Esta temática permanece pouco representada nos grupos que se dedicam à Educação Infantil, mas se nota a incorporação da criança pequena e da Educação Infantil entre as temáticas abordadas por grupos da área da Educação do Campo.

Palavras-chave: Educação Infantil. Crianças. Campo. Rural. 
Abstract

Keywords: Early childhood education of the countryside.

Service.

Settlements

Preschool

education.

Children.

Countryside.

Rural.

\section{Resumen}

Palabras Claves: Educación

Infantil. Niños. Campo. Rural.
Mapping of research groups and studies on preschool education for children residing in rural areas in the southeast region of Brazil

This article presents a mapping of articles, theses and dissertations from the field of education based on themes related to preschool education for children residing in rural areas in Brazil's Southeast Region, from 2012 to 2016. It also included a study of research groups from the area of education in the Southeast Region to verify whether the theme has been considered. In interaction with reports from the national survey "Characterization of pedagogical practices with children from ages 0 to 6 years residing in rural areas", posted on the website of the Ministry of Education, it sought to explore what has been produced on the theme since that survey. The methodology consisted of a literature review and search in a research group registry, all available on the Internet. Searches were done in the following sources: a) Directory of Research Groups from the CNPq (National Council for Scientific and Technological Development); b) reports from the national survey "Characterization of pedagogical practices with children from ages 0 to 6 years residing in rural areas"; c) database of theses and dissertations from CAPES (Coordination for the Improvement of Higher Education); and d) the website of SciELO (Scientific Electronic Library Online). The results indicated that little progress has been made and that there is still a long way to go to understand the reality of preschool children in non-urban areas. This theme continues to receive little attention from groups dedicated to preschool education, but there has been an incorporation of small children and preschool education among the themes addressed by groups working in the area of rural education.

\section{Mapeo de grupos de investigación y estudios sobre la Educación Infantil para niños residentes en áreas rurales de la Región Sudeste de Brasil}

El artículo presenta un mapeo de los artículos, tesis y disertaciones del área de la Educación que tuvieron como objeto temáticas relacionadas a la Educación Infantil para los niños residentes en áreas rurales de la Región Sudeste de Brasil, en el período de 2012 a 2016. Abarcó también un levantamiento de los grupos de investigación del área de Educación de la Región Sudeste para verificar si la temática era abarcada. En diálogo con los informes de la Investigación Nacional "Caracterización de las prácticas pedagógicas con niños de 0 a 6 años residentes en área rural", publicados en la página web del Ministerio de la Educación, objetivó conocer lo que se produjo sobre la temática después de la referida investigación. La metodología consistió en investigación bibliográfica y búsqueda en registro de grupos de investigación, todos disponibles en la web. Se realizaron búsquedas en las siguientes fuentes: a) Dirección de Grupos de Investigación del Consejo Nacional de Desarrollo Científico y Tecnológico - CNPq; b) Informe de la Investigación Nacional "Caracterización de las prácticas pedagógicas con niños de 0 a 6 años residentes en área rural"; c) banco de tesis y disertaciones de la Coordinación de Perfeccionamiento de Personal de Nivel Superior (CAPES); y d) en la página del Scientific Eletronic Library Online (SciELO). Los resultados indicaron pocos avances y que estamos distantes de conocer la realidad de los niños pequeños de áreas no urbanas. Esta temática permanece poco representada en los grupos que se dedican a la Educación Infantil, pero se nota la incorporación de niños pequeños y de la Educación Infantil entre las temáticas abordadas por grupos del área de la Educación del Campo. 


\section{Introdução}

A Educação Infantil como direito de todas as crianças brasileiras encontra nas condições de oferta às crianças residentes em áreas rurais um dos grandes desafios das políticas para a área. Como demanda e problemática que emergem nos contextos urbanos, as discussões sobre o acesso e permanência, bem como sobre as características da educação de bebês e crianças pequenas residentes em áreas rurais são ainda incipientes e carecem de maior investimento por parte do poder público, dos movimentos sociais e das instituições de pesquisa. Estudos da área da Educação Infantil demonstram que, em seu processo de construção como direito até a sua institucionalização por meio de instrumentos normativos, a temática contou com as ações de movimentos sociais e a produção acadêmica, que convergiram no que se refere às concepções e aos objetivos para as creches e pré-escolas, o que fortaleceu as lutas e permitiu conquistas importantes (SILVA, 2008). No caso da sua oferta para as populações não urbanas, também se observa a ação dos movimentos sociais do campo, que lutam não apenas pela extensão da Educação Infantil para as crianças que residem em áreas rurais mas também por uma concepção que incorpore os princípios da Educação do Campo (SILVA; PASUCH; SILVA, 2012).

Observa-se que tais movimentos, em sua articulação com uma produção teórica comprometida com os direitos e com a alteridade dos povos do campo, conquistaram a formulação de normas para a Educação do Campo e a Educação Infantil do Campo em consonância com os princípios por eles defendidos (BRASIL, 2002, 2008). Assim, considerase que o incremento da produção acadêmica e, especialmente, seu fortalecimento por meio da pesquisa institucionalizada têm grande valor, tanto para o avanço do conhecimento na área quanto para as conquistas no plano das políticas públicas de garantia dos direitos dessa população.

Estudos anteriores demonstram que a oferta da Educação Infantil para crianças residentes em áreas rurais brasileiras ainda é um assunto pouco estudado e demanda ações e investimentos de toda a sociedade brasileira, como apontado nos relatórios da Pesquisa Nacional Caracterização das práticas pedagógicas com crianças de 0 a 6 anos residentes em área rural, publicados no site do Ministério da Educação (MEC) (BRASIL; UFRGS, 2012a, 2012b, 2012c, 2012d). Considerando a importância de obter maior conhecimento sobre a realidade da área e a relevância da pesquisa para o seu reconhecimento e fortalecimento, o presente artigo tem como objetivo apresentar um mapeamento de artigos, teses e dissertações que tiveram como objeto temas relacionados à Educação Infantil para as crianças residentes 
em áreas rurais dos estados da Região Sudeste do Brasil, no período de 2012 a 2016. Abrangeu também um levantamento dos grupos de pesquisa da área da Educação de instituições de ensino superior pertencentes a esses estados, a fim de verificar se e em que medida a temática foi contemplada.

O recorte regional foi utilizado para que os resultados do mapeamento pudessem dialogar com os estudos anteriores de modo mais qualificado, tendo-se em visa os limites de um artigo. Ressalta-se ainda que se utiliza a expressão 'Região Sudeste' em referência aos estados do Espírito Santo, de Minas Gerais, do Rio de Janeiro e de São Paulo.

Conforme o primeiro volume do segundo relatório da referida Pesquisa Nacional Análise de dados secundários (BRASIL; UFRGS, 2012a), a Região Sudeste foi a que apresentou o menor percentual de população rural do país, com um índice de 7,1\%. Apesar disso, ocupava a terceira posição no número de crianças residentes em área rural, com um percentual de $15,6 \%$. Era a Região que apresentava o maior número de matrículas da Educação Básica. No entanto, em relação à Educação Infantil para crianças residentes em áreas rurais, ocupava novamente a terceira posição. No que se refere ao tempo de permanência das crianças nas creches e pré-escolas, as jornadas mais longas foram observadas em turmas de Educação Infantil das regiões Sudeste e Sul (rurais e urbanas). As regiões Centro-Oeste, Sudeste e Sul dispõem de um quadro de funções docentes composto por profissionais com formação superior em maior número do que o observado nas regiões Norte e Nordeste, nas quais a maioria das funções docentes é exercida por pessoas que não possuem o nível superior de escolaridade. Observa-se assim a complexidade em abordar a Educação Infantil para crianças residentes em áreas rurais no Brasil, considerando-se as desigualdades regionais. Mesmo com indicadores superiores em relação às demais regiões do país no que se refere à cobertura do atendimento na Educação Básica ou à qualificação docente, a Região Sudeste apresenta baixa cobertura na Educação Infantil para áreas rurais. Ainda que se reconheça que não há homogeneidade entre os estados que compõem a Região, nem entre os municípios de um mesmo estado, esse dado é revelador de um outro fator de desigualdade: a desigualdade entre campo e cidade, portanto entre as condições de vida de suas populações, especialmente no que se refere à educação escolar e, no que interessa a este artigo, à educação de bebês e crianças de até 6 anos.

Por essas e outras razões, considera-se fundamental jogar luz sobre essa realidade, o que se faz também por meio da pesquisa acadêmica, que deve manifestar seu compromisso com a diminuição da desigualdade educacional entre as crianças. Foi com esta perspectiva que se realizou a pesquisa cujas análises são apresentadas neste artigo: por meio de quais 
temáticas, onde e por quais grupos a Educação Infantil para crianças residentes em áreas rurais tem sido problematizada?

A metodologia consistiu em pesquisa bibliográfica e busca em cadastro de grupos de pesquisa, todos disponíveis na web. Foram realizadas buscas nas seguintes fontes: a) Diretório de Grupos de Pesquisa do Centro Nacional de Desenvolvimento Científico e Tecnológico $(\mathrm{CNPq}) ; \mathrm{b})$ relatórios da Pesquisa Nacional Caracterização das práticas pedagógicas com crianças de 0 a 6 anos residentes em área rural; c) banco de teses e dissertações da Coordenação de Aperfeiçoamento de Pessoal de Nível Superior (Capes); e d) site da Scientific Eletronic Library Online (SciELO). O recorte temporal foi o período de 2012 a 2016. Esta pesquisa pretendeu cobrir o período subsequente ao analisado pela Pesquisa Nacional, cujo levantamento bibliográfico se circunscreveu ao período de 1996 a 2011 (BRASIL; UFRGS, 2012a). Foram utilizados de forma combinada os seguintes descritores: 'Educação do Campo'; 'Educação Infantil do/no Campo'; 'Educação Rural'; 'Educação Infantil Rural'; 'Educação Infantil e Campo'.

Este artigo está estruturado da seguinte forma: 1) grupos de pesquisa; 2) artigos, teses e dissertações encontrados nas duas bases; 3) análise dos resultados do estudo em diálogo com os apontamentos do Relatório da Pesquisa Nacional da Região Sudeste (BRASIL; UFRGS, 2012c); e 4) considerações finais.

\section{Grupos de Pesquisa do CNPq}

A busca no diretório dos Grupos de Pesquisa do CNPq aconteceu no dia 29 de novembro de 2016. A inclusão desse levantamento da produção dos grupos foi indicada pelo primeiro relatório da Pesquisa Nacional (BRASIL; UFRGS, 2012c), que teve como foco a produção bibliográfica sobre a Educação das crianças de 0 até 6 anos residentes em área rural, visto que esta não foi uma ação contemplada na referida pesquisa. $\mathrm{O}$ objetivo ao identificar a existência de grupos ou de abordagens sobre o tema Educação Infantil para crianças residentes em áreas rurais foi averiguar a institucionalização de pesquisas sobre a temática.

Como metodologia desta busca, foi utilizada a consulta parametrizada, por meio das expressões: Educação do Campo; Educação Infantil do Campo e Educação Infantil rural. Buscaram-se: nome do grupo, nome das linhas de pesquisa e palavras-chave. Os filtros aplicados foram os seguintes: a) grande área: Ciências Humanas; b) área: Educação; c) Região Sudeste: todos os estados e todas as instituições. Apresentam-se, a seguir, os resultados para cada uma das palavras-chave.

\subsection{Resultados para a expressão "Educação do Campo"}

Foram encontrados 36 registros de grupos de pesquisa, distribuídos conforme detalhamento abaixo. 
No estado do Espírito Santo, foram encontrados 7 grupos (6 da Universidade Federal do Espírito Santo - UFES -, e 1 do Instituto Federal do Espírito Santo - IFES). Destes, somente 1 apresentava a palavra Infância ou a expressão Educação Infantil nas palavras-chave e/ou no setor de aplicação.

Em Minas Gerais, foram encontrados 14 grupos (2 da Universidade Federal de Juiz de Fora - UFJF -, 2 da Universidade Federal de Viçosa - UFV -, 4 da Universidade do Estado de Minas Gerais - UEMG -, 2 da Universidade Federal de Uberlândia - UFU -, 2 da Universidade Federal do Triângulo Mineiro - UFTM - e 2 da Universidade Federal de Minas Gerais - UFMG). Destes, 4 apresentavam a palavra Infância ou a expressão Educação Infantil nas palavras-chave e/ou no setor de aplicação.

No Rio de Janeiro, foram encontrados 8 grupos (4 da Universidade Federal Rural do Rio de Janeiro - UFRRJ -, 2 da Universidade do Estado do Rio de Janeiro - UERJ -, 1 da Universidade Federal Fluminense - UFF - e 1 do Instituto Federal Fluminense - IFF). Destes, 2 apresentavam a palavra Infância ou a expressão Educação Infantil nas palavras-chave e/ou no setor de aplicação.

Em São Paulo, foram encontrados 7 grupos (1 da Universidade Metodista de Piracicaba - Unimep -, 2 da Universidade Estadual Paulista - Unesp -, 3 da Universidade Federal de São Carlos - Ufscar - e 1 da Universidade de São Paulo - USP). Destes, 2 apresentavam a palavra Infância ou a expressão Educação Infantil nas palavras-chave e/ou no setor de aplicação.

\subsection{Resultados para a expressão "Educação Infantil"}

Considerando-se a Região Sudeste de forma agrupada, foram encontrados 67 registros na pesquisa nos grupos. Localizaram-se registros de grupos que tinham Educação Infantil no título e também de grupos dedicados a outros temas (como alfabetização). Buscou-se a presença de linhas de pesquisa sobre a Educação Infantil do Campo. Em somente 1 grupo foi encontrado o registro de uma linha de pesquisa sobre Educação Infantil em contexto rural: o Laboratório de Pesquisa em Infância, Imagens e Subjetividades da UFF. A linha de pesquisa denomina-se Educação Infantil em Contextos Rurais.

Não foram localizados registros de grupos de pesquisa utilizando-se a expressão 'Educação Infantil do Campo' e com a Região Sudeste de forma agrupada.

Observa-se que, dos 36 registros dos grupos de pesquisa da Região Sudeste localizados por meio da expressão 'Educação do Campo', 9 contêm Educação Infantil nas palavras-chave (8) ou no setor de aplicação (1). Dos 67 grupos encontrados por meio da expressão 'Educação Infantil', apenas 1 apresentou linha de pesquisa explicitamente voltada para a Educação Infantil em contextos rurais.

Observa-se que há pesquisas sobre a Educação Infantil para as crianças residentes em áreas rurais sendo desenvolvidas por pesquisadores(as) da Região Sudeste., Esses dados parecem indicar que os registros feitos pelos pesquisadores e coordenadores de grupos não têm contemplado os termos relativos aos estudos sobre infância e/ou Educação Infantil em contextos rurais. Podem indicar também a não constituição de linhas de pesquisa pelos grupos que se dedicam a essa temática, o que favorece a invisibilização do tema. Esse levantamento indica ainda que os grupos de pesquisa sobre Educação do Campo têm incluído a Educação Infantil em seu escopo de pesquisas, com $25 \%$ de registros dessa expressão. Já nos grupos que se dedicam à Educação Infantil, a baixíssima presença dos descritores 'campo' e 'rural' 
possivelmente expressa não apenas a ausência de registros mas também a sub-representação da temática entre os grupos da área.

\section{Produção bibliográfica: Artigos, teses e dissertações sobre a Educação Infantil do/no Campo}

A escolha de artigos, teses e dissertações como fontes para conhecimento da produção acadêmica sobre a Educação Infantil para crianças residentes em áreas rurais da Região Sudeste foi motivada por se tratar de resultados de pesquisa e por sua disponibilidade em bases digitais. Sabe-se da importância da produção de livros autorais e em forma de coletâneas na área da Educação de modo geral, mas esta pesquisa se restringiu às fontes acima mencionadas, considerando-se que mesmo as pesquisas desenvolvidas no âmbito da pósgraduação stricto sensu que não resultaram em publicação de artigos puderam ser localizadas no banco de teses e dissertações. Nesse caso, reconhece-se a necessidade de realizar novas pesquisas para identificar trabalhos desenvolvidos fora dos Programas de Pós-Graduação e em outras instituições, o que não foi possível nos limites desta pesquisa. Os artigos foram obtidos no site da SciELO, que reúne as principais revistas nacionais da área da Educação. Para as teses e dissertações, utilizou-se o banco de teses e dissertações da Capes. O período de publicação dos trabalhos limitou-se ao intervalo entre os anos de 2012 a 2016, tendo-se em vista que no levantamento bibliográfico da Pesquisa Nacional (BRASIL; UFRGS, 2012a) foi utilizado o recorte temporal de 1996 a 2011.

\subsection{Artigos}

A busca no site da SciELO, como dito anteriormente, levou em consideração o fato de que este site reúne as principais revistas nacionais da área de Educação. Utilizaram-se como filtros para a busca inicial o período de publicação entre 2012 e 2016 e os seguintes descritores: 'Educação do Campo'; 'Educação Infantil do/no Campo' e 'Educação Infantil Rural'; 'Educação Rural'; 'Educação Infantil e Campo'. No primeiro momento, foram encontrados 76 artigos com os filtros supracitados, porém não foi possível filtrar inicialmente a região de abrangência que interessava a este artigo. Após a leitura de todos os artigos, foi possível delimitar os trabalhos relativos aos estados da Região Sudeste do Brasil.

Com o descritor 'Educação do Campo', foram encontrados 26 artigos. Destes, 17 foram publicados em revistas da Região Sudeste, 2 foram publicados na Região Centro-Oeste; e 7, na Região Sul. Entre os 17 trabalhos publicados em revistas da Região Sudeste, nenhum discutia a Educação Infantil do/no Campo nem se dedicava a pesquisas voltadas para o conhecimento da realidade de municípios dos estados do Sudeste. Esses trabalhos tratavam de diversos temas pertinentes à Educação do Campo, a saber: multisseriação; contexto histórico da Educação do Campo; Programa Nacional do Livro Didático (PNLD) e Educação do Campo; políticas públicas para Educação do Campo; Licenciatura da Educação do Campo; Programa Nacional de Educação na Reforma Agrária (Pronera); e Escola Ativa.

As buscas com os termos 'Educação Infantil do/no Campo' e 'Educação Infantil Rural' não encontraram nenhum trabalho publicado no período de 2012 a 2016 . Importante considerar que essas expressões revelam concepções políticas sobre a educação das populações residentes em áreas rurais. De um lado, a expressão ‘Educação do Campo' revela 
uma concepção construída pelos movimentos de luta dessas populações e expressa oposição à tradição da educação rural, que se baseava na visão do campo como o símbolo do atraso a ser superado. Ao contrário, os movimentos sociais do campo buscam marcar seu lugar de grupo social e cultural capaz de gestar princípios educativos que se coadunem com os modos de vida dos diferentes povos de áreas não urbanas do Brasil. Além disso, inserem seu projeto educativo no conjunto das lutas que empreendem contra as desigualdades sociais. Nessa direção, a não localização de artigos por meio das expressões 'Educação Infantil do/no Campo' e 'Educação Infantil Rural' parece revelar a difusão dos referenciais da chamada Educação do Campo (BRASIL, 2004; 2007): por um lado, revela o abandono das ideias estigmatizantes do rural e de suas populações contidas na expressão 'educação rural' e, por outro, a compreensão de que ainda não se pode falar a priori de 'Educação Infantil do Campo', em razão de sua concepção ultrapassar a dimensão geográfica. Os debates da área, mesmo aqueles contidos na Pesquisa Nacional, utilizam por vezes a expressão 'Educação Infantil no Campo' para se referirem à localização. No entanto, no contexto da referida pesquisa, adotou-se 'Educação Infantil para crianças residentes em áreas rurais', de modo a indicar a etapa formalmente reconhecida na legislação, os sujeitos e seu local de vida. Tudo isso são indícios de que os (as) pesquisadores(as) da área da Educação Infantil que se voltam para as crianças e a oferta dessa etapa da educação em áreas rurais parecem assimilar as discussões realizadas pelo campo da Educação do Campo, que vem se firmando também nos meios acadêmicos. Como se verá a seguir, o mesmo não ocorre com outros níveis de ensino e/ou temáticas.

A busca com o termo 'Educação Rural' encontrou 33 trabalhos, entre os quais 17 artigos já haviam sido computados na busca com o descritor 'Educação do Campo'. Desse modo, foram excluídos os artigos duplicados, restando 16 trabalhos. Destes, 14 artigos foram publicados em revistas da Região Sudeste; e 2, em periódicos da Região Sul. Dos artigos analisados, 7 discutiam sobre a Educação Rural na Região Sudeste, contudo não abordavam a Educação Infantil, versando sobre: Ensino Fundamental; desenvolvimento rural; cultura popular; e formação de professores rurais (1948-1974). Esses artigos também foram excluídos da análise deste trabalho.

A última busca na SciELO utilizou o descritor 'Educação Infantil e Campo'. A partir dessa busca, foram encontrados 17 trabalhos. Destes, 12 artigos são de trabalhos sobre a realidade de municípios da Região Sudeste, 4 são da Região Sul; e 1, da Região Norte. Analisando-se os 12 artigos que tratavam de pesquisas desenvolvidas na Região Sudeste, percebeu-se que 10 não discutiam a Educação Infantil no contexto rural, portanto também foram excluídos. Sendo assim, foram analisados 2 artigos que discutem o tema que interessa a este trabalho: Educação Infantil para crianças residentes em áreas rurais. Dos 2 artigos em análise, 1 trabalho foi publicado em 2014; e o outro, em 2015.

As pesquisadoras que publicaram os artigos em análise estavam vinculadas à Pontifícia Universidade Católica de São Paulo (PUC/SP) (ROSEMBERG, 2014), à USP e à UFU (LIMA; SILVA, 2015).

Quanto às temáticas, encontramos: um artigo sobre a formação de professores e diversidade étnico-racial (ROSEMBERG, 2014), que discute a diversidade étnico-racial em escolas quilombolas e apresenta os dados da Pesquisa Nacional nessa contextualização; e o outro artigo discute a relação entre Educação Infantil em contexto rural e as famílias do campo (LIMA; SILVA, 2015). 
As análises apresentadas por Rosemberg (2014) focalizaram as implicações epistemológicas e políticas dos conceitos de igualdade/desigualdade e diversidade na Educação Infantil. A abordagem teórica utilizada pela autora apoia-se em Nancy Fraser e Antônio Flávio Pierucci e esboça um modelo para compreensão das desigualdades raciais na educação brasileira. Segundo a autora, as perspectivas teóricas foram usadas para analisar normativas e padrões de oferta da Educação Infantil do ponto de vista das relações raciais. $\mathrm{O}$ artigo apresenta as tensões da diversidade-igualdade no contexto do acesso a uma Educação Infantil de qualidade nas escolas em 'localização diferenciada', entre as quais as escolas situadas em terras indígenas, em assentamentos da Reforma Agrária e em áreas remanescentes de quilombo, privilegiando estas últimas. Nesse trabalho, a perspectiva limitou-se à análise da qualidade da oferta de Educação Infantil nessas áreas. De acordo com a autora, no que se refere aos indicadores para escolas situadas em áreas remanescentes de quilombos rurais em relação ao conjunto das escolas rurais, observam-se, com raras exceções, piores condições de oferta. Segundo Rosemberg (2014), no Censo Escolar privilegiou-se a diversidade em detrimento da igualdade.

O artigo de Lima e Silva (2015) apresenta dados de uma pesquisa realizada em uma escola rural de um município de Minas Gerais e teve como objetivo discutir a relação entre a Educação Infantil e as famílias do campo, com a finalidade de contribuir para as discussões que versam sobre a Educação Infantil em contextos rurais a partir de significações sobre essa relação. De acordo com os dados da pesquisa, no município em análise havia 13 instituições localizadas em áreas rurais que ofereciam a Educação Infantil. Ao todo, havia 374 crianças matriculadas nessas instituições do campo, o que correspondia a um percentual de $2,1 \%$ da população de crianças matriculadas nessa etapa. As autoras indicam ainda que o número de matrículas se modifica de acordo com a rotatividade das famílias das crianças. Os instrumentos de pesquisa utilizados foram a observação e a entrevista individual com 6 profissionais de educação e 5 famílias. Foi observado que a presença e a participação da família na escola são temas centrais nas discussões sobre o compartilhamento da educação e do cuidado da criança na Educação Infantil. De acordo com as autoras, as características do campo e de suas escolas, além das condições de vida e trabalho das famílias, atravessam as significações na relação entre escola-família. Desse modo, segundo as autoras, os resultados da pesquisa indicaram que é preciso observar e dar novos contornos para a relação entre as famílias do campo e a escola, a fim de se planejar e estruturar a sua presença na escola.

Pôde-se observar, por meio do mapeamento, que os trabalhos sobre a Educação Infantil no/do Campo em pesquisas desenvolvidas na Região Sudeste e publicadas na forma de artigos em periódicos nacionais ainda são escassos, o que não significa dizer que não há pesquisas nessa área. Pode-se inferir que tais produções acadêmicas estão sendo veiculadas em outros meios de divulgação científica.

Embora reduzidas (apenas dois artigos resultantes de pesquisas sobre Educação Infantil para crianças residentes em áreas rurais), a comparação com os dados da Pesquisa Nacional indica que há certa continuidade nas publicações em periódicos. A Pesquisa Nacional localizou onze artigos de abrangência nacional no recorte temporal entre 1996 e 2011, ao passo que, nesta pesquisa, buscaram-se apenas trabalhos realizados na Região Sudeste e publicados entre 2012 e 2016.

\subsection{Teses e dissertações desenvolvidas em Programas de Pós-Graduação brasileiros}


A pesquisa no banco de teses e dissertações da Capes foi iniciada por buscas amplas na área da Educação, sem o filtro das instituições da Região Sudeste. A intenção foi conhecer, pelo menos de modo quantitativo, os trabalhos desenvolvidos no país, para então compreender como a Região Sudeste comparecia neste levantamento geral. Dessa forma, pretendia-se verificar se a tendência demonstrada no levantamento da produção bibliográfica da Pesquisa Nacional, que evidenciou um grande percentual de trabalhos na Região no período de 1996 a 2011 (BRASIL; UFRGS, 2012a), manteve-se no período focalizado neste estudo.

A busca com o termo 'Educação do Campo' sem filtro de região obteve 1.024 trabalhos cuja área de concentração e avaliação fosse a Educação no período de 2012 a 2016. Selecionando-se as instituições da Região Sudeste, foram encontrados 133 trabalhos. Com as leituras dos resumos, das palavras-chave e, em alguns casos, buscando-se a expressão 'Educação Infantil' nos textos das teses e dissertações, foram obtidos 32 trabalhos que faziam referência à Educação Infantil em municípios de estados da Região Sudeste. Observou-se que alguns trabalhos, embora publicados em Programas de Pós-Graduação de instituições da Região Sudeste, apresentavam pesquisas realizadas em outras regiões. Considerando-se os limites do artigo, as análises foram restritas aos trabalhos cujos termos estivessem mais diretamente relacionados à temática da Educação Infantil do/no Campo. Ressalta-se a necessidade de outros estudos que busquem analisar quais informações destes trabalhos reunidos sob o termo 'Educação do Campo' auxiliam a compreensão da Educação Infantil para crianças residentes em áreas rurais da Região Sudeste.

Os resultados para as buscas com os termos que indicariam de forma mais direta a vinculação à Educação Infantil para as crianças residentes em áreas rurais, foram: 'Educação Infantil do Campo' (24 trabalhos); 'Educação Infantil no Campo' (8 trabalhos); e 'Educação Rural' (1 trabalho). Desse total de 33 trabalhos, 3 se repetiram, restando então 30 trabalhos, entre os quais 24 dissertações de mestrado e 6 teses de doutorado. Sobre esses 30 trabalhos, apresentam-se algumas informações que permitem formar uma visão geral das pesquisas considerando-se o ano de publicação, a temática abordada e a instituição onde foi produzida.

No ano de 2012, obtiveram-se 2 dissertações de mestrado e 1 tese de doutorado. No ano de 2013, 4 dissertações e 1 tese. No ano de 2014, 3 dissertações. No ano de 2015, 5 dissertações. E no ano de 2016, 10 dissertações e 4 teses, totalizando 30 trabalhos no período. Em relação a esse quantitativo da produção no período de 2012 a 2016, nota-se um aumento significativo em comparação com o que foi encontrado na Pesquisa Nacional (BRASIL; UFRGS, 2012a). Nos 15 anos de intervalo coberto pela referida Pesquisa, foram encontrados 62 trabalhos, entre os quais 10 teses e 52 dissertações. Destas, somente 1 doutorado e 6 
mestrados tiveram foco na Educação Infantil do/no Campo. Um dos elementos apontados no relatório da Pesquisa Nacional sinalizava o aumento da produção após os anos 2000, alertando, porém, para o risco de generalizações, tendo-se em vista que o período coberto pela série histórica era pequeno e requeria novos levantamentos.

Para o levantamento das temáticas abordadas, considerou-se o que foi colocado nos títulos dos trabalhos. Aquelas que apareceram em mais de um trabalho foram: as que buscam o ponto de vista da criança residente em área rural sobre aspectos relativos à Educação Infantil do Campo (5); aspectos relacionados ao currículo (4); políticas públicas (3); o brincar das crianças (2); formação de professores/educadores (2); e direito à educação (3). Outros temas apareceram somente em um trabalho: gestores educacionais; políticas internacionais; pré-escola; salas extensivas; estado da arte sobre infância e Educação Infantil do Campo; Educação Infantil para as crianças pequenas nas proposições do Movimento dos Trabalhadores sem Terra - MST; Educação Infantil em uma Escola de Ensino Fundamental; representações sociais da Educação Infantil do Campo por parte de mães e docentes; Fundo de Manutenção e Desenvolvimento da Educação Básica e de Valorização dos Profissionais da Educação (Fundeb); relação entre a Educação Infantil do Campo e as famílias; e produção acadêmica na década 2000-2010, o que evidencia a inclusão de aspectos que não estavam presentes na Pesquisa Nacional. Nessa pesquisa, as temáticas presentes estavam relacionadas aos processos educativos em áreas de assentamento e acampamento; aos processos de inclusão das professoras de uma instituição comunitária; à inserção de professores homens; ao processo sócio-político de municipalização da Educação Infantil; aos significados da Educação Infantil para as crianças; às trajetórias de vida e à formação de professoras; à concepção das crianças sobre a escola e suas práticas pedagógicas; e às vivências de infância (SILVA et al., 2012).

Sobre as regiões das instituições em que os trabalhos foram realizados, tem-se a seguinte distribuição:

a) Região Norte: 2 dissertações de mestrado; uma da Universidade Federal de Roraima (UFRR) e a outra da Universidade Federal do Pará (UFPA);

b) Região Nordeste: Universidade do Estado da Bahia (UNEB) (3), Universidade Federal da Bahia (UFBA) (2), Universidade Estadual de Feira de Santana (UEFS) (1) e Universidade Federal Rural de Pernambuco (UFRPE) (1), com o total de 5 dissertações e 2 teses;

c) Região Centro-Oeste: Universidade Federal de Mato Grosso do Sul (UFMS) (1), Universidade de Brasília (UnB) (1), Universidade Federal de Goiás (UFG) (1) e 
Universidade do Estado de Mato Grosso (Unemat) (1), com o total de 3 dissertações e 1 tese;

d) Região Sudeste: UFES (3), USP (2), Universidade Estadual de Campinas (Unicamp) (1), UFMG (1), UFJF (1) e Universidade de Taubaté (Unitau) (1), com o total de 7 dissertações e 2 teses;

e) Região Sul: Universidade Federal de Santa Maria (UFSM) (2), Universidade Estadual de Maringá (UEM) (1), UFSC (1), Universidade Federal do Paraná (UFPR) (1), Universidade Federal do Rio Grande do Sul (UFRGS) (1), Universidade Federal de Pelotas (UFPel) (1) e Universidade Federal do Rio Grande (Furg), com o total de 8 dissertações e 1 tese.

Em termos percentuais, verifica-se que os trabalhos publicados na Região Norte (2) representam 6,6\% do total de trabalhos (30); na Região Nordeste, 23,3\% (7), na Região Centro-Oeste, 13,3\% (4); na Região Sudeste, 30\% (9); e na Região Sul, 26,6\% (8). Essa distribuição apresenta percentuais semelhantes aos da Pesquisa Nacional, quando considerados os 63 trabalhos encontrados, que incluíam também um Trabalho de Conclusão de Curso (TCC). Conforme informações do primeiro relatório da Pesquisa Nacional (BRASIL; UFRGS, 2012a; SILVA et al., 2012), verifica-se que a maioria dos trabalhos foi produzida em Universidades vinculadas às regiões Sudeste e Sul, que, juntas, somaram 41 trabalhos (aproximadamente 65\% da produção de teses, dissertações e TCCs). Nas Universidades das Regiões Norte, Nordeste e Centro-Oeste, foram produzidos, no total, 22 trabalhos, sendo a Região Norte a de menor concentração. Apesar desta semelhança, é importante ressaltar que houve uma diminuição no percentual de pesquisas desenvolvidas na Região Sudeste, que, na Pesquisa Nacional, representavam 39,7\% e, neste estudo, representam apenas $30 \%$. Verifica-se ainda um aumento no percentual de trabalhos publicados na Região Nordeste, que, na Pesquisa Nacional, representavam 15,9\% e, neste estudo, representam $23,3 \%$.

Outra semelhança está na dispersão do número de Universidades a que pertencem os Programas de Pós-Graduação. Na Pesquisa Nacional, 36 Universidades respondiam por um conjunto de 63 trabalhos e, neste estudo, 24 Universidades respondem por um conjunto de 30 trabalhos. A frequência de trabalhos em uma mesma Universidade também se modificou, pois na Pesquisa Nacional a UFPA liderava com 5 trabalhos, seguida por UFSCar, UFMG, UFPR, UFRGS, Universidade do Vale do Itajaí (Univali) e UNEB, com 3 trabalhos cada. Neste estudo, lideram a frequência a UNEB e a UFES, com 3 trabalhos cada, seguidas por UFBA, USP e UFSM, com 2 trabalhos cada. Conforme a equipe da Pesquisa, a dispersão parecia 
indicar que não havia grupos de referência na produção acadêmica sobre Educação Infantil em contexto rural (SILVA et al., 2012), hipótese reforçada com a mudança nas Universidades que lideram a frequência de trabalhos publicados identificada neste estudo. De todo modo, a presença da UNEB nos dois levantamentos parece indicar que, nessa instituição, há uma continuidade no estudo da temática.

\subsection{Teses e Dissertações desenvolvidas em Programas de Pós-Graduação dos estados da} Região Sudeste do Brasil

Após essa primeira visão geral dos 30 trabalhos publicados, tratou-se das 7 dissertações e das 2 teses publicadas em instituições do Sudeste, com o objetivo de apresentar mais detalhes das pesquisas e complementar as informações levantadas na Pesquisa Nacional (BRASIL; UFRGS, 2012c). Os trabalhos foram agrupados conforme o estado de origem.

\subsubsection{Espírito Santo - ES}

As três dissertações estão vinculadas à UFES sob a orientação da professora Valdete Côco, na linha de pesquisa 'Cultura, currículo e formação de educadores'. Lovatti (2014) focalizou a formação e a atuação docentes e constatou que a Educação Infantil do Campo vem ganhando uma visibilidade progressiva nas políticas públicas locais. A autora informa que a pesquisa sinalizou indicativos de avanços relacionados aos aspectos de acompanhamento pedagógico das instituições, manutenção dos espaços físicos e propostas de formação continuada. Dentre os desafios e demandas de investimento constatados, destacou a formação das profissionais como prioridade. Ressaltou a especificidade da formação com a discussão dos diversos temas vinculados ao contexto da Educação Infantil do Campo, para que, desse modo, pudesse contribuir para a construção coletiva das instituições.

Vieira (2016) também pesquisou a formação continuada tendo como foco os educadores que atuavam em assentamentos de Reforma Agrária. A pesquisa demonstrou que o atendimento às crianças do campo residentes em assentamentos de Reforma Agrária no contexto do ES era reduzido em relação à demanda e oferecido em salas anexas às escolas de Ensino Fundamental da rede estadual. Salientou também que a formação dos educadores acontecia nos vários espaços e tempos em que atuavam, destacando os espaços de formação organizados pelo Setor de Educação do MST como alicerces de uma formação com vinculação e pertencimento ao campo. Por fim, indicou a necessidade de este Setor reconhecer a Educação Infantil em áreas de assentamento como direito das crianças pequenas, pautando-o e lutando por ele. 
Silva (2013) focalizou a iniciativa das salas extensivas de Educação Infantil do Campo no município de Pancas/ES, com o objetivo de caracterizar essa oferta e conhecer as demandas postas ao trabalho docente. A pesquisa indicou as salas extensivas como uma das possibilidades de inclusão das crianças pequenas do campo no sistema de ensino com a ampliação da oferta. Entretanto ressaltou também os desafios neste quadro de expansão, como as dificuldades ligadas à infraestrutura, ao processo educativo e aos processos formativos dos profissionais.

\subsubsection{Minas Gerais - MG}

A única dissertação de Minas Gerais foi desenvolvida na UFJF (UCHOA, 2015) e orientada pelo professor Dileno Dustan Lucas de Souza, na linha de pesquisa 'Gestão de políticas públicas e avaliação educacional'. A pesquisa de Uchoa (2015) teve como objetivo compreender como o município de Miradouro implementava a política da Educação Infantil, para verificar se as ações realizadas atendiam às especificidades da criança que vive no campo. As considerações da pesquisa indicam que houve um esforço em construir uma educação coadunada com os valores, a cultura e o modo de vida da criança do campo, mas que estes elementos precisam ser potencializados. Reconhece também que esse esforço faz parte de um processo complexo e em construção, que requer o envolvimento de todos, reconhecimento da diversidade local e o respeito pela infầncia e suas diferentes concepções.

\section{$\underline{\text { 3.3.3 Rio de Janeiro - RJ }}$}

A única tese de instituição do estado do Rio de Janeiro foi defendida na UFRJ, sob a orientação da professora Lígia Maria Motta Lima Leão de Aquino, na linha de pesquisa 'Infầncia, juventude e educação'.

O estudo de Oliveira (2016) teve como objetivo compreender as perspectivas acerca das crianças na Educação Infantil em contextos rurais presentes nas produções acadêmicas da última década, de 2000 a 2010, com análises construídas a partir das categorias 'infância', 'Educação Rural' e 'Educação do Campo'. O levantamento dos trabalhos levou em consideração os dados contidos na obra Produção acadêmica nacional sobre a Educação Infantil das crianças residentes em área rural (1996-2011). As análises das produções indicaram que houve o entendimento, por parte da maioria dos autores, de que a Educação Infantil se constitui num direito, com o reconhecimento das crianças como sujeitos de direitos. As análises também assinalaram a necessidade de avançar em termos de superação da educação rural com vistas à constituição de uma Educação do Campo que contemple os anseios das populações do campo. 


\subsubsection{São Paulo - SP}

Entre os quatro trabalhos vinculados a instituições de São Paulo, 2 teses foram defendidas na USP, sob a orientação da professora Ana Paula Soares da Silva, na linha de pesquisa 'Psicologia, processos culturais e subjetivação' (LIMA, 2012; ARAÚJO, 2015). Na Unicamp, foi defendida uma dissertação, sob a orientação da professora Ana Luiza Bustamante Smolka, sem indicação da linha de pesquisa (VASCONCELOS, 2016). ${ }^{1} \mathrm{Na}$ Unitau, foi defendida uma dissertação, sob a orientação da professora Edna Maria Querido de Oliveira, na linha de pesquisa 'Políticas educacionais e inclusão escolar' (SILVA, 2016).

O estudo de Araújo (2015) teve como objetivo geral compreender as significações dos gestores educacionais sobre o atendimento às crianças do campo na Educação Infantil, identificando como organizavam este atendimento. Além disso, também buscou compreender como municípios da Mesorregião de Ribeirão Preto (SP) ofertavam a Educação Infantil às crianças de 0 a 5 anos moradoras de áreas rurais. Sobre esta oferta, os resultados indicaram que a quase totalidade dos municípios a realizava a contento, prioritariamente para a préescola e para as crianças de 4 e 5 anos de idade. $O$ atendimento das crianças de 0 a 3 anos, quando ocorria, era realizado em creche localizada na área urbana. Mesmo a oferta de préescola ocorria preferencialmente em área urbana. Verificou-se, na pesquisa, o investimento em transporte escolar para a área urbana em contraposição ao investimento em atendimento na própria área rural. Em alguns municípios, não havia monitores para acompanhar as crianças no trajeto entre a escola e a casa. Apesar de os municípios alegarem possuir propostas pedagógicas, não as fundamentavam em legislações relativas à Educação do Campo; existia investimento em formação continuada, mas poucos municípios ofereciam formação específica. Em um dos municípios em que foi realizada a pesquisa qualitativa, identificou-se a adoção de política pública que priorizava o atendimento da criança do campo de 4 a 5 anos em pré-escola localizada em área rural. As gestoras tomavam a valorização da cultura do campo como norteadora das práticas específicas nestas pré-escolas e apresentavam significações que transitavam entre a preocupação em manter aspectos gerais da política de Educação Infantil para todas as crianças e a busca por adaptações de aspectos específicos da Educação Infantil para as crianças de áreas rurais. Assumindo posição diferente da afirmada pela Secretaria Municipal de Educação, as gestoras consideraram necessário desvincular a gestão das pré-escolas localizadas no campo das escolas de Educação Infantil localizadas na

\footnotetext{
${ }^{1}$ A pesquisa que deu origem à dissertação de Vasconcelos (2016) ocorreu em uma comunidade rural do agreste pernambucano e, por essa razão, não será considerada na interlocução com os dados da Pesquisa Nacional (BRASIL; UFRGS, 2012c).
} 
cidade e também significaram como negativa a indicação política para cargo de diretor escolar.

O objetivo da tese de Lima (2012) foi investigar as significações de profissionais da Educação Infantil de escolas localizadas em área rural e de famílias do campo sobre a relação estabelecida entre essas famílias e as referidas escolas. A pesquisa foi realizada em um município de Minas Gerais que possuía 13 escolas que ofereciam Educação Infantil no Campo. As análises indicaram que a relação entre as famílias e as instituições no contexto investigado era constituída por elementos que apresentavam semelhanças e diferenças em comparação ao contexto urbano e a outros contextos rurais. Esta relação era atravessada por elementos como: o tipo de área rural e suas características geográficas e econômicas, a diversidade das famílias, suas demandas e concepções, as relações de trabalho no campo e as condições de vida semelhantes e/ou distintas das urbanas. Em função disso, a pesquisa indica a necessidade de que as concretudes e características de cada rural, assim como suas (des)continuidades em outros contextos, sejam tidas como aspectos importantes a serem considerados por todos os atores que almejam a melhoria da relação entre a Educação Infantil e as famílias do campo.

A dissertação de Silva (2016) buscou identificar as representações sociais da Educação Infantil do/no Campo por parte de docentes e mães de alunos, em uma cidade do Vale do Paraíba paulista. Os resultados indicaram que os aspectos da convivência e interação com outras crianças foram os motivos pelos quais docentes e mães atribuíam importância à Educação Infantil. Na discussão dos resultados da pesquisa, a autora reconhece a dificuldade de definir qualidade, por ser um conceito relativo, baseado em valores, necessidades, ideias e perspectivas. Ficou evidenciada a existência de critérios de qualidade distintos entre professores e mães, mas também a partilha de concepções e práticas entre família e escola no entrelaçamento das diferentes vozes da comunidade escolar,. Sendo assim, indica-se que os princípios de qualidade que norteiam as ações na instituição de Educação Infantil no Campo devam considerar a história dos sujeitos e a interação entre eles.

A análise da produção de teses e dissertações desenvolvidas nos Programas de PósGraduação brasileiros no intervalo entre os anos de 2012 e 2016 obteve um número de trabalhos superior ao encontrado na Pesquisa Nacional, que cobriu 15 anos (1996-2011) (BRASIL; UFRGS, 2012a), atestando o crescimento do investimento e da visibilidade da temática entre os pesquisadores da Educação do Campo. Uma possível explicação para o aumento pode ser a influência da própria Pesquisa Nacional, que proporcionou o encontro de pesquisadores da Educação Infantil e da Educação do Campo, possibilitando assim a articulação entre essas duas áreas e a emergência das discussões da Educação Infantil do/no 
Campo. Observa-se também que, durante a Pesquisa Nacional, foram realizados Seminários Nacionais, que ajudaram a divulgar e a dar visibilidade à temática, além da publicação de um livro e dos relatórios com seus resultados, todos disponíveis na página do MEC. Verifica-se ainda a ampliação dos aspectos e do escopo de análise nos trabalhos localizados por esta pesquisa quando comparados aos trabalhos selecionados pela Pesquisa Nacional.

No que se refere especificamente aos trabalhos desenvolvidos em Programas de PósGraduação da Região Sudeste, observa-se maior concentração no Programa de Pós-Graduação em Educação da UFES e no Programa de Pós-Graduação em Psicologia da USP - campus Ribeirão Preto. As temáticas abordadas envolveram aspectos da política educacional para as crianças de 0 a 5 anos residentes em áreas rurais, aspectos do trabalho e da formação docente e aspectos das relações com as famílias das crianças. E um dos trabalhos foi dedicado às concepções sobre a criança e a infância nesses contextos.

\section{Considerações Finais}

As análises sobre os Grupos de Pesquisa registrados no Diretório do CNPq, das teses e dissertações disponíveis no Banco da CAPES e dos artigos disponíveis na SciELO, focalizando o período de 2012 a 2016, indicaram avanços em ritmo muito aquém do necessário. Observa-se que a produção acadêmica voltada para os contextos não urbanos é incipiente, com reduzido número de pesquisas e ainda muito pouco institucionalizadas, como se verificou pela inexpressiva presença da temática nos Grupos registrados no CNPq.

Como o escopo desta pesquisa limitou-se a abordar os trabalhos desenvolvidos nos Programas de Pós-Graduação ou publicados em periódicos da base SciELO, é possível que muitos trabalhos desenvolvidos em instituições não universitárias ou em cursos de graduação e especialização tenham ficado de fora. No entanto, ainda que isto tenha de fato ocorrido, é possível afirmar que estamos muito distantes de conhecer a realidade das crianças pequenas de áreas não urbanas e que avançamos muito pouco nas discussões sobre as concepções de práticas de cuidado e educação em contexto escolar para crianças de áreas rurais. Dentre os avanços, destaca-se o início da incorporação da criança pequena e da Educação Infantil entre as temáticas abordadas por grupos da área da Educação do Campo. O contrário, no entanto, não se evidenciou, estando a abordagem das crianças residentes em áreas rurais muito pouco representadas nas temáticas dos Grupos que se dedicam à Educação Infantil.

Quanto aos artigos dedicados à Educação Infantil para crianças residentes em áreas rurais, considerando-se todos os descritores utilizados, foram localizados 59 trabalhos em periódicos de todo o Brasil, realizados nas diferentes regiões. O recorte na Região Sudeste e a 
leitura dos trabalhos reduziu a apenas 2 os artigos dedicados à Educação Infantil em contextos rurais, resultantes de pesquisas desenvolvidas em municípios de estados da Região. Considerando-se o número reduzido de trabalhos, também as temáticas se revelaram em pequeno número. Observa-se, no entanto, os esforços de pesquisadoras(es) em analisar as ações das políticas de Educação Infantil para crianças residentes em áreas rurais, a questão da docência nesse contexto e também a abordagem das práticas cotidianas de cuidado e educação.

No caso das teses e dissertações, verificou-se avanço em relação ao período analisado na Pesquisa Nacional Caracterização das práticas pedagógicas com crianças de 0 a 6 anos residentes em área rural (BRASIL; UFRGS, 2012a), com aumento do número de trabalhos desenvolvidos, tendo-se encontrado, no período de 2012 a 2016, um número de trabalhos superior ao obtido no período de 1996 a 2011. Verificou-se também que a Região Sudeste segue liderando o número de trabalhos desenvolvidos na Pós-Graduação stricto sensu, permanecendo, quando comparada à Pesquisa Nacional, a dispersão entre Programas de PósGraduação de todo o país. Observou-se também mudança na liderança entre os Programas de Pós-graduação, no que se refere ao número de pesquisas desenvolvidas sobre a temática. Somente o Programa de uma Universidade (UNEB) manteve-se na posição em que se encontrava em 2012, evidenciando continuidade do trabalho com a temática.

As análises dos trabalhos que se voltaram para experiências de municípios da Região Sudeste revelaram certa abrangência de temáticas. Encontraram-se trabalhos que analisaram a Educação Infantil em assentamentos da Reforma Agrária; sobre elementos das políticas, como a priorização do atendimento à pré-escola e, consequentemente, menor investimento na creche; o atendimento de crianças das áreas rurais em escolas urbanas e a questão do transporte; as questões da docência nessa etapa; as possibilidades de oferta considerando-se a característica de dispersão populacional no campo; questões relacionadas à precariedade da infraestrutura; as representações de professoras e mães de áreas rurais sobre a Educação Infantil; e as relações entre Educação Infantil e famílias do campo.

Considerando-se a importância da produção acadêmica sobre a temática para o seu reconhecimento social, é preciso que os(as) pesquisadores(as) da área deem maior visibilidade ao tema, especialmente no que se refere ao Diretório do $\mathrm{CNPq}$, uma agência de fomento à pesquisa.

Destaca-se, finalmente, a discussão proposta por Fúlvia Rosemberg (2014), na qual problematiza a tensão entre igualdade e diversidade no trato das questões raciais. Para a autora, há prevalência da diversidade sobre a igualdade. A mesma referência pode e deve ser discutida no que se refere à igualdade de direitos das crianças dos contextos urbanos e não 
urbanos e à consideração da diversidade cultural dos povos do campo. Embora presente de alguma forma nos trabalhos sobre a temática, conforme discutido relativamente ao uso das expressões 'Educação Rural' e 'Educação no/do Campo', parece ainda muito frágil a compreensão a respeito das condições adequadas para oferta de Educação Infantil para crianças de áreas rurais. Questões como as temporalidades, a dispersão da população no espaço, os sentidos da Educação Infantil para as crianças e suas famílias, entre outras, continuam como desafios políticos e epistemológicos para a construção de referências que deem conta do direito de todas as crianças, tendo como referência tanto a diversidade quanto a igualdade.

\section{Referências}

ARAUJO, Thaise Vieira de. Educação Infantil do Campo e gestores educacionais. 2015. 200 f. Dissertação (Mestrado em Psicologia) - Universidade de São Paulo, Ribeirão Preto, 2015.

BRASIL. Conselho Nacional de Educação. Câmara de Educação Básica. Resolução no 1 , de 3 abril de 2002. Diretrizes Operacionais para a Educação Básica nas Escolas do Campo. Diário Oficial da União: Brasília, DF, Seção 1, p. 32, 9 abr. 2002. Disponível em: https://bit.ly/2r9rjzB. Acesso em: 18 nov. 2016.

BRASIL. Referenciais para uma Política Nacional de Educação do Campo. Caderno Subsídio. Brasília: MEC/Secad, 2004.

BRASIL. Educação do Campo: diferenças mudando paradigmas. Caderno 2. Brasília: MEC/Secad, 2007.

BRASIL. Conselho Nacional de Educação. Câmara de Educação Básica. Resolução Complementar n ${ }^{0}$ 2, 28 de abril de 2008. Diretrizes complementares, normas e princípios para o desenvolvimento de políticas públicas de atendimento da Educação Básica do Campo. Diário Oficial da União: Brasília, DF, Seção 1, p. 81, 29 abr. 2008. Disponível em: https://bit.ly/2LePbsy. Acesso em: 18 nov. 2016.

BRASIL. Ministério da Educação; UNIVERSIDADE FEDERAL DO RIO GRANDE DO SUL (UFRGS). Pesquisa Nacional Caracterização das práticas educativas com crianças de 0 a 6 anos de idade residentes em áreas rurais. Análise dos dados quantitativos das condições educacionais de crianças de 0 a 6 anos de idade residentes em área rural. Dados secundários. [S. l.]: MEC, 2012a. v. 1. Disponível em: https://bit.ly/2LhIqpQ. Acesso em: 19 nov. 2016.

BRASIL. Ministério da Educação; UNIVERSIDADE FEDERAL DO RIO GRANDE DO SUL (UFRGS). Pesquisa Nacional Caracterização das práticas educativas com crianças de 0 a 6 anos de idade residentes em áreas rurais. Relatório Síntese. [S. l.]: MEC, 2012b. v. 2. Disponível em: https://bit.ly/2DyROkD. Acesso em 20 nov. 2016.

BRASIL. Ministério da Educação; UNIVERSIDADE FEDERAL DO RIO GRANDE DO SUL (UFRGS). Pesquisa Nacional Caracterização das práticas educativas com crianças de 0 a 6 anos de idade residentes em áreas rurais. Mapeamento e análise das realidades investigadas na Região Sudeste. [S. l.]: MEC, 2012c. v. 3. Disponível em: https://bit.ly/2Ya0mIg. Acesso em: 19 nov. 2016.

BRASIL. Ministério da Educação; UNIVERSIDADE FEDERAL DO RIO GRANDE DO SUL (UFRGS). Pesquisa Nacional Caracterização das práticas educativas com crianças de 0 a 6 anos 
de idade residentes em áreas rurais. Produção acadêmica nacional sobre a Educação Infantil das crianças residentes em área rural (1996-2011) - Região Sudeste. [S. l.]: MEC, 2012d. Disponível em: https://bit.ly/2Pb3EXE. Acesso em: 18 nov. 2016.

LIMA, Luciana Pereira de. A relação entre a Educação Infantil e as famílias do campo. 2012. 129 f. Tese (Doutorado em Psicologia) - Universidade de São Paulo, Ribeirão Preto, 2012.

LIMA, Luciana Pereira de; SILVA, Ana Paula Soares da. A relação entre a Educação Infantil e as famílias do campo. Associação Brasileira de Psicologia Escolar e Educacional, São Paulo, v. 19, n. 3, p. 475-483, dez. 2015. ISSN 2175-3539. DOI: http://dx.doi.org/10.1590/2175-3539/2015/0193875. Disponível em: https://bit.ly/2P9Bw6W. Acesso em: 18 nov. 2016.

LOVATTI, Renata Rocha Grola. Docência e formação na Educação Infantil do Campo: dizeres docentes. 2014. 195 f. Dissertação (Mestrado em Educação) - Universidade Federal do Espírito Santo, Vitória, 2014.

OLIVEIRA, Denise Rangel Miranda de. Educação Infantil em contextos rurais: perspectivas presentes na produção acadêmica da última década (2000-2010). 2016. 136 f. Tese (Doutorado em Educação) - Universidade Federal do Rio de Janeiro, Rio de Janeiro, 2016.

ROSEMBERG, Fúlvia. Educação Infantil e relações raciais: a tensão entre igualdade e diversidade. Caderno de Pesquisa, São Paulo, v. 44, n. 153, set. 2014. ISSN 0100-1574. DOI: http://dx.doi:10.1590/198053142856. Disponível em: https://bit.ly/33FclhS. Acesso em 18 nov. 2016.

SILVA, Ana Paula Soares da; SOUZA, Tatiana Noronha; SILVA, Ana Cecília Oliveira; SILVA, Fernanda. Lacerda; SILVA, Juliana Bezon; LIMA, Luciana Pereira; CARVALHO, Regiane Sbroion de; ARAÚJO, Thaise Vieira. Produção acadêmica nacional sobre Educação Infantil das crianças residentes em área rural. In: BARBOSA, Maria Carmen Silveira; SILVA, Ana Paula Soares da; PASUCH, Jaqueline; LEAL, Fernanda de Lourdes Almeida; SILVA, Isabel de Oliveira e; FREITAS, Maria Natalina Mendes; ALBUQUERQUE, Simone Santos de (org.). Oferta e demanda de Educação Infantil no campo. 1. ed. Porto Alegre: Evangraf, 2012. v. 1, p. 291-331.

SILVA, Celia Gomez Sardinha da. As representações sociais da Educação Infantil no/do Campo por docentes e mães de alunos, em uma cidade do vale do paraíba paulista. 2016. $295 \mathrm{f}$. Dissertação (Mestrado Profissional em Educação) - Universidade de Taubaté, Taubaté, 2016.

SILVA, Divina Leila Soares. Salas extensivas de Educação Infantil do Campo: uma experiência no município de Pancas, ES. 2013. 188 f. Dissertação (Mestrado em Educação) -Universidade Federal do Espírito Santo, Vitória, 2013.

UCHOA, Patricia Rejane da Silva. A política da Educação Infantil pública do campo. 2015. 138 f. Dissertação (Mestrado em Educação) - Universidade Federal de Juiz de Fora, Juiz de Fora, 2015.

VASCONCELOS, Beatriz Nogueira Marques de. Modos de participação e apropriação da cultura: vida, escola e mídia na Educação Infantil do Campo. 2016. 142 f. Dissertação (Mestrado em Educação) - Universidade Estadual de Campinas, Campinas, 2016.

VIEIRA, Marle Aparecida Fideles de Oliveira. Educação Infantil do Campo e formação continuada dos educadores que atuam em assentamentos. 2016. 211 f. Dissertação (Mestrado em Educação) - Universidade Federal do Espírito Santo, Vitória, 2016. 